\title{
Review
}

\section{Cytokine regulation of epithelial permeability and ion transport}

\section{Introduction}

The intestinal epithelium serves as a dynamic barrier which, in the course of its normal function, maintains regulated uptake of nutrients and water at the same time as excluding potential pathogens. Enteropathies, including inflammatory bowel disease (IBD) result in, or perhaps even from, perturbed epithelial function. Despite the idiopathic nature of IBD, it is apparent that much of the pathophysiology, tissue damage and symptomatology of these disorders are due to inappropriate or exaggerated immune reactions. ${ }^{12}$ Cytokines are, inter alia, regulators of both innate and acquired immunity, so therefore it is not surprising that exaggerated effects of cytokines in acute or chronic inflammatory states may be due to unregulated production of pro-inflammatory cytokines or inadequate synthesis of anti-inflammatory cytokines. Indeed, increases in cytokine concentrations in models of enteric inflammation or IBD are well documented. ${ }^{3}$ Here, we provide an overview of cytokine regulation of epithelial ion transport and permeability, highlighting, where appropriate, the potential of the epithelium to modulate mucosal immune reactions and its own function.

Relatively few studies have demonstrated cytokine effects on epithelial function in vivo or by examining intestinal tissue responses ex vivo. ${ }^{45}$ Several features contribute to difficulties with interpretation of such studies. Firstly, cytokines act in a coordinated interplay of often redundant, pleiotropic and occasionally opposing actions. ${ }^{6}$ Secondly, given the complex intercellular signalling that occurs within the gut, ${ }^{7}$ cytokine effects may involve other, non-cytokine mediators. ${ }^{8-10}$ Finally, virtually every putative mediator of inflammation has been implicated in diseases of the intestine, representing at one time the academic pharmacologist's dream and the therapist's nightmare.

The advent of epithelial cell lines, principally the tumour derived T84, Caco-2 and HT-29 cell lines, has offered opportunities to study influences of cytokines on epithelial function by taking a reductionist approach. These cell lines, when grown on permeable filters, form polarised, high electrical resistance monolayers (rodent derived epithelial cells have been extensively use to examine epithelial restitution, cytokine production and other parameters. However, these cells do not generally form monolayers suitable for studies in Ussing chambers). Although there are several disadvantages inherent with using cell lines ${ }^{11}$ such investigations have made a significant contribution to the awareness of cytokine regulation of epithelial physiology in general, and ion transport and permeability in particular. Moreover, cell lines are now a basic tool in cell biology, allowing both generation and testing of novel hypotheses which may unveil potential therapeutic targets which require subsequent validation by whole tissue or animal studies in advance of experimental clinical manipulation(s).

The enteric epithelial cell layer regulates normal homoeostasis, innate immunity and regulation of acquired immunity at both sensory and effector levels. ${ }^{12-14}$ As such, the epithelium may play a role in the immunological outcome of luminal exposure to antigens resulting in tolerance, pro- tective immunity or hypersensitivity reactions. There exists a substantial literature on the capacity of epithelial cells to produce bioactive cytokines and other immunoregulatory molecules either constitutively or in response to stimuli including other cytokines or microorganisms. ${ }^{14-18}$ The epithelium is now identified as both target and source of cytokines (fig 1). Epithelial derived cytokines have the potential to play an autocrine role or to influence adjacent non-epithelial cells. For example, epithelial cells can synthesise interleukin (IL) 6 , a cytokine that can inhibit lipopolysaccharide (LPS) induced IL-1 and tumour necrosis factor (TNF) $\alpha$ in vivo and in vitro. IL-6 is also a major inducer of tissue inhibitor of matrix metalloproteinase (TIMP) and here it is noteworthy that much of the tissue damage associated with $\mathrm{T}$ cells is due to the release of metalloproteinases. ${ }^{19}$

\section{Epithelial permeability}

Intestinal permeability is a rather loose but clinically useful $^{20}$ term used to denote integrity of the epithelial barrier in vivo which may be compromised in malnutrition, ${ }^{21}$ infection $^{22}{ }^{23}$ and in pathological conditions including IBD and coeliac disease. ${ }^{24}$ In vitro, permeability to macromolecules is readily determined quantitatively ${ }^{25}$ and can be used to study modulation of epithelial permeability by extracellular macromolecules including cytokines. Transepithelial electrical resistance (TER; and its inverse conductance) is determined by the Ohmic relation and has been used as an index of barrier permeability. However, there is not always a direct correlation between electrical resistance and permeability to marker molecules. $^{26}$

Luminal material crosses the epithelial sheet via the transcellular or paracellular pathways. Tight junctions form a circumferential seal at the luminal pole of adjacent epithelial cells and are the rate limiting factor regulating paracellular permeability. ${ }^{27}$ A growing body of evidence has recently accumulated showing that such junctions express a high degree of plasticity and may be greatly attenuated in disease states. ${ }^{28}$ Most findings to date implicate proinflammatory cytokines as agents which reduce barrier integrity.

\section{EXOGENOUS CYTOKINES}

Direct actions of cytokines may readily be examined pharmacologically in model epithelia. Addition of interferon (IFN) $\gamma$, but not IFN- $\alpha$, to the basolateral surface of T84 monolayers causes a significant increase in paracellular

Abbreviations used in this paper: IBD, inflammatory bowel disease; IL, interleukin; LPS, lipopolysaccharide; TNF, tumour necrosis factor; TIMP, tissue inhibitor of matrix metalloproteinase; TER, transepithelial electrical resistance; IFN, interferon; TGF, transforming growth factor; PMBC, peripheral blood mononuclear cells; SEB, Staphylococcus aureus enterotoxin B; FGF, fibroblast growth factor; EGF, epidermal growth factor; IGF, insulin-like growth factor; IEL, human intraepithelial lymphocytes; PG, prostaglandin; CFTR, cystic fibrosis transmembrane regulator; MLCK, myosin light chain kinase; NF-кB, nuclear factor $\kappa B$; STAT, signal transduction and activators of transcription; MALT, mucosa associated lymphoid tissue. 

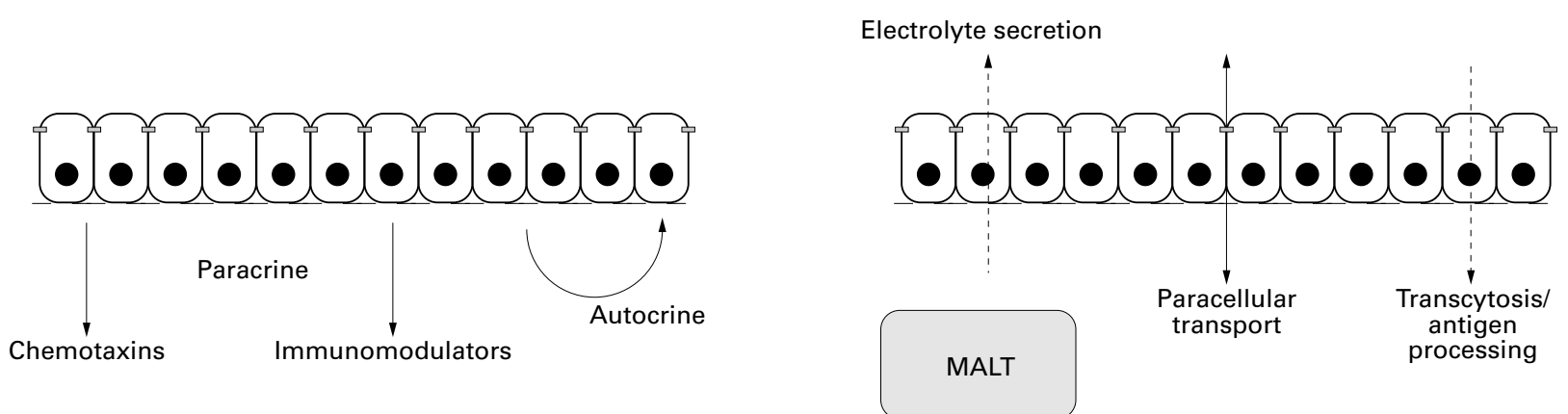

Figure 1 Intestinal epithelial cells express various cytokines either constitutively or in response to stimuli including other cytokines or microorganisms. Epithelial cells also express receptors for a number of different cytokines. Thus cytokines (and other soluble mediators) produced by epithelial cells may play an autocrine role or may influence adjacent non-epithelial cells (A). Conversely, epithelial cells which express cytokine receptors coupled to an appropriate signal transduction system may be influenced by cytokines generated from other cell types (B).

permeability which is accompanied by disruption of the peri-junctional F-actin. ${ }^{29}{ }^{30}$ Pharmacological sequestering of G-actin (the monomeric precursor of F-actin) also profoundly affects transepithelial resistance. ${ }^{31}$ Focal discontinuities in peri-junctional F-actin are a common feature in epithelial monolayers with perturbed permeability characteristics.

Interleukin 4 and IL-13, which have broadly similar biological functions, both cause increased epithelial permeability. ${ }^{32}$ However, unlike IL-4, IL-13 does not affect ion transport in T84 cells. These divergent effects of IL-4 and IL-13 could be due to interaction with different receptors. Another possibility is that both cytokines may bind to the same receptor (IL-4 and IL-13 receptors have a structurally homologous subunit ${ }^{33}$ ), with IL-13 triggering only part of the signal transduction cascade that is inducible by IL-4.

TNF- $\alpha$ concentrations are increased in a variety of inflammatory disorders and the use of $\mathrm{TNF}-\alpha$ neutralising antibody has been found to be an effective therapeutic modality in some patients with Crohn's disease. ${ }^{34} 35$ However, anti-TNF- $\alpha$ immunotherapy clinical trials have not examined changes in intestinal permeability before and after treatment. TNF- $\alpha$ increases endothelial permeability and studies with a variety of epithelia, including the renal cell line LLC-PK1 (in which protein kinase C was implicated in the TNF- $\alpha$ evoked increase in permeability ${ }^{36}$ ) suggest that epithelial barrier function is reduced by TNF- $\alpha{ }^{37}$ However, observations from four independent laboratories have shown that low dose TNF- $\alpha(<10 \mathrm{ng} / \mathrm{ml})$ has no effect on T84 permeability, ${ }^{29}{ }^{38-40}$ whereas another report indicates that TNF- $\alpha$ can potentiate the drop in T84 transepithelial resistance induced by IFN- $\gamma .{ }^{41}$ Additionally, chronic TNF- $\alpha$ treatment of T84 cells has been found to increase permeability $(100 \mathrm{ng} / \mathrm{ml} /$ day for four days increased transepithelial inulin flux). ${ }^{42}$ Studies with the HT29-19A epithelial cell line showed responsiveness to TNF- $\alpha$ which increased transepithelial permeability which was further enhanced synergistically in the presence of low concentrations of IFN- $\gamma$. Such synergism was suggested to be a consequence of induction of TNF- $\alpha$ receptors by IFN- $\gamma .{ }^{43}{ }^{44}$

Certain cytokines have been shown, in contrast to the pro-inflammatory molecules, to prevent or reverse impaired permeability. IFN- $\gamma$ induced increases in $\mathrm{T} 84$ permeability can be prevented by concomitant treatment with transforming growth factor (TGF) $\beta 1^{30}$ or a chronic IL-10 regimen $(100 \mathrm{ng} / \mathrm{ml} /$ day, three days prior to IFN- $\gamma$ treatment and then daily additions of IL-10 for another four days). ${ }^{42}$ In co-culture studies where T84 monolayers were exposed to peripheral blood mononuclear cells (PBMC) activated by the bacterial superantigen, Staphylococcus aureus enterotoxin B (SEB), the evoked increase in epithelial permeability was partially abrogated by TGF- $\beta 2$ and IL-10. ${ }^{45}$ However, the beneficial effects of IL-10 were most likely due to inhibition of an immune response. ${ }^{47} 48$

Other mitogenic cytokines, including fibroblast growth factor (FGF), TGF- $\alpha$ and $-\beta$, and epidermal growth factor (EGF), influence permeability of normal epithelia by promoting continuous cell turnover, and of damaged epithelia by encouraging wound repair by a process of restitution. ${ }^{48-50}$ Insulin-like growth factors (IGF) have also been found to increase permeability across confluent T84 monolayers via a protein synthesis dependent mechanism. ${ }^{51}$ In addition to regulating cell proliferation, these growth factors have non-mitogenic actions on intestinal tissue which are protective and aid digestive functions. ${ }^{52}$

\section{CELL DERIVED CYTOKINES}

In reconstructing more complex systems, co-culture studies where epithelial monolayers and immune cells or immunocyte derived supernatants are juxtaposed results in disruption of epithelial barrier function. T84 cell monolayers co-cultured with mucosal-like lymphocytes, ${ }^{53}$ anti-CD3 or SEB activated PBMC, ${ }^{39} 45$ endotoxin activated monocytes $^{38}$ or human intraepithelial lymphocytes (IEL) or an IEL cell line ${ }^{40}$ invariably display a decrease in transepithelial resistance within 24 hours of co-culture. Although cell-cell contact may be a requirement for full expression of such intercellular cross talk, there is evidence to suggest that paracrine signalling occurs as quantitatively similar increases in epithelial permeability are elicited by conditioned media from the immune cell cultures. For example, supernatants from antigen stimulated PBMC from children allergic to cow's milk decrease the TER of HT-29 monolayers. ${ }^{54}$ Given the rapidity of this response, which was maximal within 24 hours, it seems unlikely that it is due to the singular activity of any of the cytokines considered earlier which require longer exposure to generate effects. Indeed, it is rather unlikely that epithelia in situ would be exposed to a single cytokine. Exposure of model epithelia to co-cultured immunocytes or immune cell derived conditioned media which contain mixtures of cytokines in the relative proportions in which they are produced by the immune cell are, at least in principle, better 
mirrors of native mucosae than using single cytokines to elicit biological responses. We suggest that immune mediated alterations in epithelial permeability are due to the combinatorial effects of multiple mediators, including some which may yet have to be identified, where the stoichiometry and sequence of mediator release may be crucial. Several lines of evidence support these arguments. For instance, in HT-29 monolayers, the increased paracellular permeability and altered tight junction structure induced by TNF- $\alpha$ was enhanced by co-treatment with low dose IFN $-\gamma .^{55}$ Also pharmacological blockade of the effects of single cytokines failed to prevent significantly the actions of IEL supernatant. ${ }^{33} 53$ Finally, IELs produce at least two molecules that differentially modulate epithelial permeability, a factor(s) $<30 \mathrm{kDa}$ that causes a rapid (within four hours) $30 \%$ drop in resistance and a larger molecule(s) $(>30 \mathrm{kDa})$, the effect of which was slower in onset and caused a dramatic loss of epithelial barrier function (reduced by $\sim 90 \%$ ). ${ }^{33}$

Molecules other than cytokines may contribute to signalling cascades which result in altered epithelial permeability. For instance, tissue and cell culture studies have shown that nitric oxide can regulate epithelial permeability ${ }^{56}$ and ion transport. ${ }^{57}$ Evidence has been presented implicating nitric oxide as the final mediator in IFN- $\gamma$ evoked disruption of epithelial barrier function. ${ }^{8}$ This raises the issue of active involvement of the epithelium, and indeed the effects of IFN- $\gamma$ are only observed after more than 24 hours of culture and are protein synthesis dependent. Also, 5-ASA significantly reduced the IFN- $\gamma$ induced increased transepithelial flux of mannitol (a marker of paracellular permeability) across HT-29-19A monolayers. ${ }^{9}$ The authors suggest that this effect was due to the 5-aminosalicylic acid competing for the IFN- $\gamma$ receptor, but the disruption of arachidonic acid metabolism may also contribute. TNF- $\alpha$ and bacterial infection can result in increased epithelial arachidonic acid metabolism and prostaglandin synthesis, ${ }^{10}{ }^{58}$ begging the question whether epithelial derived lipid metabolites exert autocrine effects on epithelial permeability and ion secretion? In fact, bacterial infection of HT-29 cells evoked epithelial prostaglandin (PG) $\mathrm{E}_{2}$ and $\mathrm{PGF}_{2 \alpha}$ production, and transfer of conditioned media from the infected cells to naive epithelial monolayers evoked a transient increase in electrogenic electrolyte transport similar to that caused by $\mathrm{PGE}_{2}{ }^{58}$

\section{Transcytosis and antigen presentation}

Cytokine modulation of transcytosis by intestinal epithelial cells is a likely event, consistent with a role for cytokines and epithelial cells in the sensory arm of adaptive immunity. Soluble factors and immune cell-epithelial cell contact are required for the formation of $\mathrm{M}$ cells that overlay the Peyer's patches, ${ }^{59}$ creating a portal of entry for bacteria and particulate antigens. ${ }^{60} \mathrm{M}$ cell density is increased in vivo in response to exposure to bacteria, ${ }^{61}{ }^{62}$ perhaps as a consequence of local generation of cytokines induced by bacterial infection which, although they interact with epithelial cells in different ways ${ }^{63}$ seem to generate a rather conserved set of responses including cytokine generation. ${ }^{14}$ Further support for cytokine participation in antigen uptake, presentation and processing comes from observations (i) that IFN- $\gamma$, and to a lesser extent $\mathrm{TNF}-\alpha$, enhances HLA-DR expression in T84 cells, ${ }^{64}$ increasing the potential of such cells, in vivo, to play a role in antigen processing ${ }^{65}$ and (ii) that inactivation of genes in the TNF/ lymphotoxin ligand and receptor system prevents normal organisation of intestinal Peyer's patches. ${ }^{66-68}$
Intact antigen may also cross enterocytes, which are more abundant than $\mathrm{M}$ cells. ${ }^{60}$ Regulation of transepithelial permeability by absorption enhancers which have been investigated for increasing oral bioavailability of drugs may result in delivery of antigenic material (e.g. gut microflora or indeed the drug itself) to the antigen processing compartments of the lamina propria. Inappropriate entry into the mucosal compartment of otherwise contained luminal entry could, at least in principle, lead to other pathology as a consequence of altered permeability and/or immune status in IBD. Reports of associated conditions range from arthropathies ${ }^{69}$ to autism. ${ }^{70}$ Intestinal epithelial cells seem to satisfy most of the criteria by which they may be considered as antigen presenting cells. ${ }^{71}$

\section{Epithelial ion transport}

Transepithelial vectorial electrolyte movement creates driving forces for directed water movement and results from the coordinated activity of ion channels, transporters and pumps, which have polar distributions in the cell membrane. ${ }^{72}$ Extremes of electrogenic ion transport can result in malabsorptive or secretory diarrhoea or constipation, often in response to extracellular molecules which influence epithelial cell activity.

Electrophysiological studies studies using single (epithelial) cell types tend to show few rapid or direct effects of cytokines on electrogenic ion transport. IFN- $\gamma$ and IL-4 have no direct affect on baseline ion transport in the T84 model of $\mathrm{Cl}^{-}$secretion, but both dramatically reduce the ability of the cells to secrete $\mathrm{Cl}^{-}$vectorially in response to a range of directly acting secretagogues. ${ }^{32}{ }^{73}$ Early studies correlated changes in ion transport characteristics evoked by IFN- $\gamma$ with changes in membrane proteins ${ }^{73}$ and more recently a reduction in the cystic fibrosis transmembrane regulator has been reported..$^{32}$ Co-culture of confluent T84 monolayers with mucosal-like lymphocytes or anti-CD3 or SEB activated immune cells results in reduced secretory responsiveness. ${ }^{39} 453$ T84 monolayers exposed to conditioned media from activated immune cells also display diminished responses to secretory stimuli which are apparent six hours after exposure and are maximal by 18-24 hours after treatment. The low levels of IFN- $\gamma$ in the conditioned media $^{53}$ and the rapidity of the response implies that the dysregulated epithelial ion transport is not due solely to IFN- $\gamma$ and is likely due to the effects of other mediators acting alone or in concert with IFN- $\gamma$.

Several pro-inflammatory cytokines are pro-secretory in intact, native mucosal preparations in vitro. For example, IL- $1,{ }^{74}{ }^{75} \mathrm{IL}-3,{ }^{74}$ and TNF- $\alpha^{76}{ }^{77}$ have been found to stimulate epithelial ion secretion. In each case, the effects of the cytokines were found to be indirect with the change in ion transport being mediated by prostaglandins from subepithelial cells. Similarly, co-culture studies using T84 epithelial cells revealed that ion transport events evoked by TNF- $\alpha$ and known secretagogues were modulated by the presence of myofibroblasts. ${ }^{78}$ Data have been reported which illustrate stimulation of T84 ion transport following 24-48 hours of co-culture with human monocytes activated with endotoxin and the bacterial tri-peptide, formyl-met-leu-phe. ${ }^{38}$ The response was accounted for by electrogenic chloride secretion and could be inhibited by neutralisation of TNF- $\alpha$. The influence of TNF- $\alpha$ seems to be an autocrine action on the monocytes. Contrary effects have been found when endotoxin activated alveolar macrophages were co-cultured with lung epithelium; this resulted in reduced ion transport due to diminished $\mathrm{Na}^{+}$ movement. ${ }^{79}$ Patients receiving IL-2 immunotherapy can develop diarrhoea although it is not clear whether this is a direct action on epithelial cells as IL-2 does not directly 
affect T84 barrier function. ${ }^{29}$ However, IL-2 receptors have been demonstrated on isolated epithelial cells and the rat IEC. 6 cell line, upon which IL-2 has biphasic effects on proliferation rates. ${ }^{80}$

Interleukin 10 exerts an antisecretory influence on gut epithelium. Thus, there is a drop in rat jejunal and ileal ion transport in response to IL-10, and the tissues exposed to IL-10 display diminished responses to carbachol (cholinergic agonist) and forskolin which evoke electrogenic $\mathrm{Cl}^{-}$secretion via $\mathrm{Ca}^{2+}$ and cAMP, respectively. ${ }^{81}$ It is not clear whether inhibition of ion secretion by IL-10 may contribute to its potential as a treatment for IBD.

Epithelial cells exposed to activated immune cells in culture or recombinant cytokines (IFN- $\gamma$, IL- 4 and TNF- $\alpha$ ) show focal condensation and redistribution of their filamentous (F)-actin. Elegant studies by Madara and coworkers have demonstrated that stabilisation of epithelial F-actin reduces cAMP mediated $\mathrm{Cl}^{-}$secretion, but not $\mathrm{Ca}^{2+}$ mediated events, ${ }^{82}$ and that this is due to lowered activity of the $\mathrm{Na}^{+} / \mathrm{K}^{+} / 2 \mathrm{Cl}^{-}$transporter. ${ }^{83}$ Thus, in addition to an inhibitory effect on the cystic fibrosis transmembrane regulator (CFTR), ${ }^{32}$ it is tempting to speculate that IFN- $\gamma$ effects on epithelial ion transport may be due, at least in part, to modulation of cytoskeletal elements that affect ion transport across the basolateral membrane or to an influence on intracellular signalling cascades.

Other studies of note include the demonstration of increased glucose and $\mathrm{NaCl}$ absorption in rabbit intestine in response to $\mathrm{EGF}^{84}$ and $\mathrm{EGF}$ inhibition of $\mathrm{Ca}^{2+}$ mediated (in response to carbachol or thapsigargin) $\mathrm{Cl}^{-}$secretion in T84 cells via phosphatidyl-inositol-3-kinase. ${ }^{85} 86$ In contrast, rat alveolar epithelium treated with EGF displayed increased baseline Isc due to active $\mathrm{Na}^{+}$transport that was sensitive to inhibition of tyrosine kinase activity. ${ }^{87}$

\section{Signal transduction}

There is a general paucity of information relating specifically to signal transduction events and cytokine regulation of epithelial ion transport and permeability. Enteropathogenic Escherichia coli infection of T84 cell monolayers results in an increase in permeability and a concomitant increase in phosphorylation of the myosin light chain. This change in epithelial permeability was prevented by inhibition of myosin light chain kinase (MLCK) activity by ML-9 and increased permeability was elicited by retroviral transfection of the catalytic domain of MLCK into kidney epithelial cells. ${ }^{88} \mathrm{~A}$ role for MLCK has not been determined in immune modulation of epithelial permeability in the way it has been characterised in response to bacterial infection.

As therapeutic usefulness of cytokines or blocking antibodies may be limited by their pharmacokinetics, a more effective approach may be to direct therapy towards common signal transduction pathways used by or in the generation of cytokines. ${ }^{89}{ }^{90}$ Gut epithelial cells infected with Helicobacter pylori ${ }^{91}$ or treated with IL-1 $\beta$ or TNF- $\alpha^{92}$ mobilise nuclear factor $\kappa \mathrm{B}(\mathrm{NF}-\kappa \mathrm{B})$, which has been linked to IL-8 production. Increasing evidence implicates $\mathrm{NF}-\kappa \mathrm{B}$ as a critical transcription factor in chronic inflammatory disease and local administration of antisense oligonucleotides to $\mathrm{NF}-\kappa \mathrm{B}$ can abrogate murine experimental colitis. ${ }^{90}$ Signal transduction and activators of transcription (STAT) proteins dimerise and are tyrosine phosphorylated by Janus kinases prior to dissociation from the receptorligand complex and translocation to the nucleus. ${ }^{93}$ Few studies have explored STAT protein expression in gut epithelial cells; a single report examined STAT3 activity in gut epithelial cells in response to IL-15. ${ }^{94}$ The hypothesis that $\mathrm{NF}-\kappa \mathrm{B}$ and/or STAT proteins govern changes in epi-

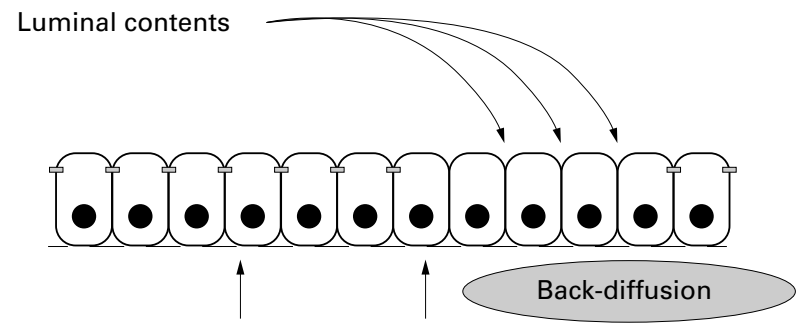

Generation of pro-inflammatory cytokines

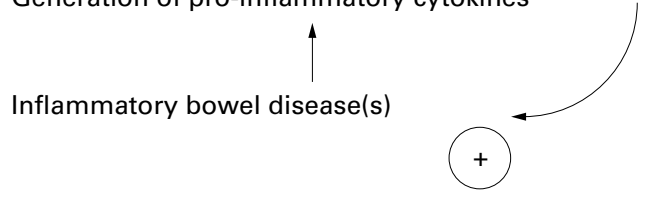

Figure 2 Impaired epithelial permeability, whether in response to cytokines or other stimuli, reduces barrier function. Increased exposure to luminal contents will activate lamina propria cells with consequent generation of pro-inflammatory cytokines. These may exacerbate the "leakiness" of the epithelium which can both promote and sustain inflammation.

thelial ion secretion and permeability remains largely untested.

Regulation of mucosal inflammation and protection Cytokine induced epithelial expression of immune accessory molecules imparts upon the epithelium the capacity to influence the progress of inflammation. IFN- $\gamma, \mathrm{TNF}-\alpha$ and other stimuli can upregulate cytokine and chemokine secretion, thus providing signals for recruitment and activation of neutrophils, monocytes and lymphocytes. ${ }^{95} 96$ Cytokine regulation of epithelial permeability may play a role in the pathogenesis of mucosal damage in IBD as abnormal and uncontrolled immune responses to microbial products and luminal antigens have been implicated in

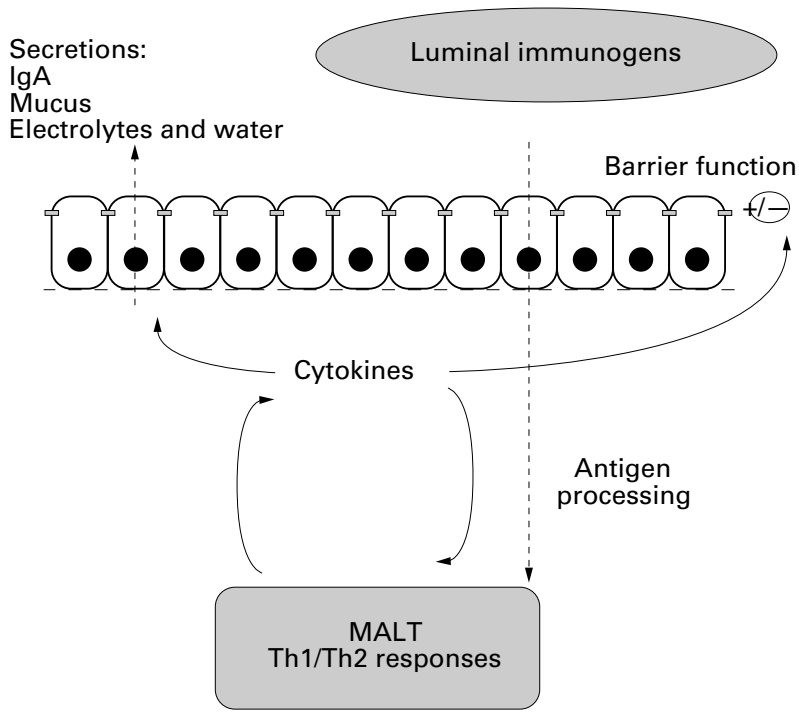

Figure 3 Cytokines and mucosal protection. The epithelium is involved in deployment of a number of effector mechanisms of innate and adaptive immunity. In terms of sensory function, antigen delivery requires trafficking (and perhaps processing) of antigens across the epithelial barrier. Locally active cytokines may influence antigen sampling in a number of ways. For example, by altering epithelial permeability or alternatively by enhancing $M$-cell differentiation. Furthermore, the nature and magnitude of an immune response will be governed by the local cytokine environment. 
tissue damage and these findings have been supported by studies on cytokine deficient mice. ${ }^{97-98}$ Pathogen exposure to mucosal surfaces elicits epithelial responses which upregulate inflammation. ${ }^{99} \mathrm{~A}$ variety of bacteria and their excreted/secreted products have direct effects on epithelial ion transport and permeability ${ }^{23}{ }^{100}$ and release of cytokines during bacterial infection may impact directly on epithelial function. Thus, following a stimulus which generates local production of cytokines, enhanced epithelial permeability permits back-diffusion of luminal contents which, in the case of normally contained bacteria, ${ }^{101}$ may sustain the cytokine production. Such a positive feedback loop may contribute to the chronic nature of IBD (fig 2).

Delivery of antigens to mucosa associated lymphoid tissue (MALT) is a primary event in initiating protective mucosal immune responses and is an attractive goal in development of oral vaccines. In this regard cytokines may play a dual role (fig 3). Firstly, in antigen sampling by altering epithelial permeability or by enhancing $M$ cell differentiation. ${ }^{59}$ Secondly, cytokines acting within MALT will regulate the nature of the immune response. ${ }^{102} 103$ Development of effective vaccination procedures directed against organisms that enter the body through the gastrointestinal tract (or vaccine delivery via the oral route for systemic immunity) represent active areas of research with enormous potential for therapeutic and commercial exploitation. Mucosally applied antigens are often ineffective immunogens. ${ }^{104}$ However, appropriate adjuvants may be used to manage the delivery as well as the type and magnitude of immune response to luminal immunogens. ${ }^{105}$ For example, IL-12 which is a potent inducer of T cell cytokines, especially IFN- $\gamma^{106}$ which seems to be an effective oral adjuvant when delivered with specific vaccines. ${ }^{107}$ As IL-12 and other cytokines are expressed and actively released in Crohn's disease ${ }^{108}$ this may account for enhanced permeability to macromolecules in an environment predisposed to generate Th1 type responses. In addition, immunological tolerance to commensal intestinal flora seems to be compromised in IBD. ${ }^{109}$ In terms of mucosal vaccines, manipulations to achieve Th1, Th2 or a combination of responses must be considered carefully not only in generating appropriate protection but also in preventing untoward side effects.

Gene therapy for intestinal conditions is an exciting prospect. Recently, adenoviral gene transfer methodology ${ }^{110}$ has been used to introduce an NF- $\mathrm{NB}$ super-repressor protein into gut epithelial cells in vitro, resulting in a diminution of their production of proinflammatory molecules. ${ }^{111}$ The therapeutic implication of this is obvious, and indeed such an approach has already been used to introduce the CFTR gene into airway epithelium. ${ }^{112}$ However, the critical issues include: (1) Is this a strategy that can be tailored to the treatment of chronic disease? (2) Can genes be introduced to the gut epithelium in vivo? (3) Can the longer-lived crypt stem cells, rather than villous enterocytes, be targeted? There may however be some cause for optimism. Using an adenoviral construct encoding a marker protein, systemic administration resulted in detectable levels of the marker protein in murine colonic crypt cells. However, this successful transfer into colonic crypt cells only occurred in immunosuppressed mice. ${ }^{113}$ Coyle et al have shown significantly enhanced efficiency of adenovirus mediated gene delivery to intestinal epithelia when Caco-2 monolayers were treated with IL-1 $\beta$, a cytokine which is known to increase expression of integrins which are involved in tight junction formation. ${ }^{114}$

\section{Concluding comments}

In this brief synopsis we have illustrated that cytokines directly and indirectly influence epithelial ion transport and permeability. What is perhaps most evident is the fact that with at least 30 known cytokines/growth factors, we have only begun to recognise the impact of cytokines on epithelial function. Indeed one of the major tasks facing enteric pharmacologists/physiologists is the dissection of pathways which transfer information and coordinate enteric responses to an extraordinary range of stimuli. Studies at subcellular, cellular and tissues levels are now possible to investigate how cytokines interact with each other and with non-cytokine neuroimmune mediators to regulate homoeostasis in the intestine. Such knowledge will be essential for the rational development of new treatment regimens.

D M McKAY

Intestinal Disease Research Programme, HSC-3N5, Department of Pathology, McMaster University, 1200 Main Street West, Hamilton, Ontario, Canada L8N $3 Z 5$ email:mckayd@fhs.mcmaster.ca

A W BAIRD

Department of Pharmacology, University College Dublin, Belfield Campus,

Dublin, Ireland

email:abaird@macollamh.ucd.ie

1 Braegger CP, MacDonald TT. Immune mechanisms in chronic inflammatory bowel disease. Ann Allergy 1994;72:135-41.

2 Radford-Smith G, Jewell DP. Cytokines and inflammatory bowel disease. Baillieres Clin Gastroenterol 1996;10:151-64.

3 Brynskov J, Nielsen OH, Ahnfelt-Ronne I, et al. Cytokines in inflammatory bowel disease. Scand F Gastroenterol 1992;27:897-906.

4 Remick DG Kunkel SL. Pathophysiologic alterations induced by tumor necrosis factor. Int Rev Exp Pathol 1993;34:7-25.

5 Garside P, Bunce C, Tomlinson RC, et al. Analysis of enteropathy induced by tumour necrosis factor alpha. Cytokine 1993;5:24-30.

6 Arend WP. Inhibiting the effects of cytokines in human diseases. Adv Intern Med 1995;40:365-94.

7 Perdue $\mathrm{MH}, \mathrm{McKay} \mathrm{DM}$. Integrative immunophysiology in the intestinal mucosa. Am f Physiol 1994;267:G151-65.

8 Unno N, Menconi MJ, Smith M, et al. Nitric oxide mediates interferongamma induced hyperpermeability in cultured human intestinal epithelial monolayers. Crit Care Med 1995;23:1170-6.

9 Di Paolo MC, Merrett MN, Crotty B, et al. 5-aminosalicylic acid inhibits the impaired epithelial barrier function induced by gamma interferon. Gut impaired epithelial

10 Gustafson-Svard C, Tagesson C, Boll R, et al. Tumour necrosis factor $\alpha$ potentiates phospholipase A2 release and arachidonic acid metabolism in cultured intestinal epithelial cell (INT 407). Scand $\mathcal{F}$ Gastroenterol 1993;28: 323-30.

11 McKay DM, Philpott DJ, Perdue MH. In vitro models in inflammatory bowel disease research - a critical review. Aliment Pharmacol Ther 1997;11 (suppl 3):70-80.

12 Castro GA, Arntzen CJ. Immunophysiology of the gut: a research frontier for integrative studies of the common mucosal immune system. Am $\mathcal{F}$ Physiol 1993;265:G599.

13 Brandtzaeg P, Halstensen TS, Kett K, et al. Immunobiology and immunopathology of human gut mucosa: humoral immunity and intraepithelial lymphocytes. Gastroenterology 1989;97:1562.

14 Kagnoff MF, Eckmann L. Epithelial cells as sensors for microbial infection. 7 Chin Invest 1997;100:6-10.

15 Tilg H, Dinarello CA, Mier JW. IL-6 and APPs: anti-inflammatory and immunosuppressive mediators. Immunol Today 1997;18:428-32.

16 Barton BE. IL-6: insights into novel biological activities. Clin Immunol Immunopathol 1997;85:16-20.

17 Sheth R, Anderson J, Sato T, et al. Rotavirus stimulates IL-8 secretion from cultured epithelial cells. Virology 1996;221:251-9.

18 Eckmann L, Kagnoff MF, Fierer J. Epithelial cells secrete the chemokine interleukin-8 in response to bacterial entry. Infect Immunol 1993;61:456974.

19 Pender SLF, Tickle SP, Docherty AJP, et al. A major role for matrix metalloproteinases in T cell injury in the gut. F Immunol 1997;158:1582-90.

20 Meddings JB. Intestinal permeability in Crohn's disease. Aliment Pharmacol Ther 1997;11(suppl 3):47-56.

21 Welsh FKS, Farmery SM, MacLennan K, et al. Gut barrier function in malnourished patients. Gut 1998;42:396-401.

22 Fink MP. Effect of critical illness in microbial translocation and gastrointestinal mucosa permeability. Semin Respir Infect 1994;9:256-60.

23 Lewis SA, Berg JR, Kleine TJ. Modulation of epithelial permeability by Lewis SA, Berg JR, Kleine TJ. Modulation of epithelial per
extracellular macromolecules. Physiol Rev 1995;75:561-89.

24 Bjarnason I, MacPherson A, Hollander D. Intestinal permeability: an overview. Gastroenterology 1995;108:1566-81. 
25 Artursson P, Karlsson J. Correlation between oral drug absorption in humans and apparent drug permeability coefficients in human intestinal epithelial cells. Biochem Biophys Acta 1991;175:880-5.

26 Balda MS, Whitney JA, Flores C, et al. Functional disassociation of paracellular permeability and transepithelial electrical resistance and disruption of the apical-basolateral intramembrane difusion barrier by expression of a mutant tight junction membrane protein. f Cell Biol 1996; 134:1031-49.

27 Anderson JM, Van Itallie CM. Tight junctions and the molecular basis for regulation of paracellular permeability. Am f Physiol 1995;269:G467-75.

28 Madara JL, Parkos CA, Colgan SP, et al. The movement of solutes and cells across tight junctions. Ann NY Acad Sci 1992;664:47-60.

29 Madara JL, Stafford J. Interferon-gamma directly affects barrier function of cultured intestinal epithelial monolayers. F Clin Invest 1989;83:724-7.

30 Planchon SM, Martins CAP, Guerrant RL, et al. Regulation of intestinal barrier function by TGF- $\beta 1$. F Immunol 1994;153:5730-9.

31 Matthews JB, Smith JA, Hrnjez BJ. Effects of F-actin stabilization or disassembly on epithelial $\mathrm{Cl}^{-}$secretion and Na-K-2Cl cotransport. Am f Physiol 1997;272:C254-62.

32 Zund G, Madara JL, Dzus A, et al. Interleukin-4 and interleukin-13 differentially regulate epithelial chloride secretion. F Biol Chem 1996;271:74604.

33 Hilton DJ, Zhang J-G, Metcalf D, et al. Cloning and characterisation of a binding subunit of the interleukin 13 receptor that is also a component of the interleukin 4 receptor. Proc Nat Acad Sci USA 1996;93:497501

34 Targan SR, Hanauer SB, van Deventer SJH, et al. A short-term study of chimeric monoclonal antibody cA2 to tumor necrosis factor $\alpha$ for Crohn's disease. N Engl f Med 1997;337:1029-35.

35 Stack WA, Mann SD, Roy AJ, et al. Randomised controlled trial of CDP571 antibody to tumour necrosis factor- $\alpha$ in Crohn's disease. Lancet 1997;349: $521-4$.

36 Mullin JM, Laughlin KV, Marano CW, et al. Modulation of tumour necrosis factor-induced increase in renal (LLC-PK1) transepithelial permeability. Am f Physiol 1992;263:F915-24.

37 Mullin JM, Smock KV. Effect of tumor necrosis factor on epithelial tight junctions and transepithelial permeability. Cancer Res 1990;50:2172-6.

38 Zareie M, McKay DM, Kovarik G, et al. Monocyte/macrophages evoke epithelial dysfunction: indirect role of tumor necrosis factor $\alpha$. Am f Physiol 1998;275:C932-9.

39 McKay DM, Croitoru K, Perdue MH. T cell monocyte interactions regulate epithelial physiology in a co-culture model of inflammation. Am f Physiol 1996;270:C418-28

40 Taylor CT, Murphy A, Kelleher D, et al. Changes in barrier function of a model intestinal epithelium by intraepithelial lymphocytes requires new protein synthesis by epithelial cells. Gut 1997;40:634-40

41 Taylor CT, Dzus AL, Colgan SP. Autocrine regulation of epithelial permeability by hypoxia: role for polarized release of tumor necrosis factor alpha. Gastroenterology 1998:114:657-68.

42 Madsen KL, Lewis SA, Tavernini MM, et al. Interleukin 10 prevents cytokine-induced disruption of T84 monolayers barrier integrity and limits chloride secretion. Gastroenterology 1997;113:151-9.

43 Hiribarren A, Heyman M, L'Helgouac'h A, et al. Effect of cytokines on the epithelial function of a human carcinoma cell line HT29 cl 19A. Gut 1993; 34:616-20.

44 Tsujimoto M, Yip YK, Vilocek J. Interferon-gamma enhances expression of cellular receptors for tumour necrosis factor. F Immunol 1986;136: 2441-44.

45 McKay DM, Singh PK. Superantigen-activation of immune cells evokes epithelial (T84) transport and barrier abnormalities via interferon- $\gamma$ and tumour necrosis factor- $\alpha$. Inhibition of increased permeability, but not diminished secretory responses by transforming growth factor $\beta 2$. F Immunol 1997;159:2382-90.

46 Lu J, Philpott DJ, Saunders PR, et al. Epithelial transport and barrier abnormalities evoked by superantigen-activated immune cells are inhibited by IL-10, but not IL-4. F Pharm Exp Ther 1998;287:128-36.

47 Van Deventer SJH, Elson CO, Fedorak RN. Multiple doses of intravenous interleukin 10 in steroid-refractory Crohn's disease. Gastroenterology 1997; 113:383-9.

48 Ciacci C, Lind SE, Podolsky DK. Transforming growth factor $\beta$ regulation of migration in wounded rat intestinal epithelial monolayers. Gastroenterology 1993;105:93-101.

49 Dignass AU, Podolsky DK. Cytokine modulation of intestinal epithelial cell restitution: central role of transforming growth factor beta. Gastroenterology 1993;105:1323-32.

50 Nusrat A, Parkos CA, Liang TW, et al. Neutrophil migration across model epithelia: monolayer disruption and subsequent events in epithelial repair. Gastroenterology 1997;113:1489-500

51 McRoberts J, Riley N. Regulation of T84 cell monolayer permeability by insulin like growth factors. Am F Physiol 1992;262:C207-13.

52 Uribe JM, Barrett KE. Nonmitogenic actions of growth factors: an integrated view of their role in intestinal physiology and pathophysiology. Gastroenterology 1997;112:255-68.

53 Kaoutzani P, Colgan SP, Cepek KL, et al. Reconstitution of cultured intestinal epithelial monolayers with a mucosal derived $\mathrm{T}$ lymphocyte cell line: modulation of epithelial phenotype dependent on lymphocyte basolateral medulation of epithelial phenotype dependent on ly

54 Heyman M, Darmon N, Dupont C, et al. Mononuclear cells form infants allergic to cow's milk secrete tumour necrosis factor $\alpha$, altering intestinal unction. Gastroenterology 1994;106:1514-23.

55 Rodriguez P, Heyman M, Candalh C, et al. Tumour necrosis factor- $\alpha$ induces morphological and functional alterations of intestinal HT29 cl.19A cell monolayers. Cytokine 1995;7:441-8.

56 Alican I, Kubes P. A critical role for nitric oxide in intestinal barrier function and dysfunction. Am F Physiol 1996;270:G225-37.

57 Gaginella T, Kachur J, Tamai H, et al. Reactive oxygen and nitrogen metabolites

58 Eckmann L, Stenson WF, Savidge TC, et al. Role of intestinal epithelial cells in the host secretory response to infection by invasive bacteria: bacterial entry induces epithelial prostaglandin $\mathrm{H}$ synthase-2 expression and prostaglandin $\mathrm{E}_{2}$ and $\mathrm{F}_{2 \alpha}$ production. $\mathcal{F}$ Clin Invest 1997;100:296-309.
59 Kerneis S, Bogdanova A, Kraehenbuhl J-P, et al. Conversion by Peyer's patch lymphocytes of human enterocytes into $M$ cells that transport bacteria. Science 1997;277:949-52.

60 Neutra MR, Frey A, Kraehenbuhl J-P. Epithelial M cells: gateways for mucosal infection and immunization. Cell 1996;86:345-8.

61 Savidge TC, Smith MW, James PS, et al. Salmonella-induced M-cell formation in germ-free mouse Peyer's patch tissue. Am f Pathol 1991;139:17784

62 Borghesi C, Regoli M, Bertelli E, et al. Modifications of the follicle associated epithelium by short term exposure to a non-intestinal bacterium. F Pathol 1996;180:326-32.

63 Galan JE, Bliska JB. Cross talk between bacterial pathogens and their host cells. Ann Rev Cell Dev Biol 1996;12:221-55.

64 Hershberg R, Nepom GT. Regulation of antigen presentation by an intestinal epithelial cell line. F Clin Invest 1997;100:204-15.

65 Mayer L, So LP, Yio XY, et al. Antigen trafficking in the intestine. Ann NY Acad Sci 1996;778:28-35.

66 Neuman B, Luz A, Pfeffer K, et al. Defective Peyer's patch organogenesis in mice lacking the $55-\mathrm{kD}$ receptor for tumor necrosis factor. $f$ Exp Med 1996;184:259-64

67 Mayrhofer G. Peyer's patch organogenesis-cytokines rule, OK? Gut 1997; 41:707-9.

68 Pasparakis M, Alexopoulou L, Grell M, et al. Peyer's patch organogenesis is intact, yet formation of $\mathrm{B}$ lymphocyte follicles is defective in peripheral lymphoid organs of mice deficient for tumor necrosis factor and $55-\mathrm{kDa}$ receptor. Proc Natl Acad Sci USA 1997;94:6319-23.

69 Orchard T, Jewell DP. Pathophysiology of intestinal mucosa. Aliment Pharmacol Ther 1997;11 (suppl 3):10-6.

70 Wakefield AJ, Murch SH, Anthony A, et al. Ileal-lymphoid-nodular hyperplasia, non-specific colitis, and pervasive developmental disorder in children. Lancet 1998;351:637-41.

71 Mayer L. Current concepts in mucosal immunity. I. Antigen presentation in the intestine: new rules and regulations. Am f Physiol 1998;274:G7-9.

72 Barrett KE, Dharmsathaphorn K. Secretion and absorption: small intestine and colon. In: Yamada T, Alpers DH, Owyang C, Powell DW, Silverstein FE, eds. Textbook of gastroenterology. Philadeplhia: JB Lippincott Co., 1991: 265-94.

73 Holmgren J, Frylund J, Larsson H. Gamma-interferon mediated down regulation of electrolyte secretion by intestinal epithelial cells: a local immune mechanism? Scand f Immuml 1989;30:499-503.

74 Chiossone DC, Simon PL, Smith PL. Interleukin-1: effects on rabbit ileal mucosal ion transport in vitro. Eur f Pharmacol 1990;180:217-28.

75 Chang EB, Musch M, Mayer L. Interleukins 1 and 3 stimulate anion secretion in chicken intestine. Gastroenterology 1990;98:1513-24.

76 Kandil HM, Berschneider HM, Argenzio RA. Tumour necrosis factor $\alpha$ changes porcine intestinal ion transport through a paracrine mechanism involving prostaglandins. Gut 1994;35:934-40.

77 Schmitz H, Fromm M, Bode $\mathrm{H}$, et al. Tumour necrosis factor- $\alpha$ induced $\mathrm{Cl}^{-}$ and $\mathrm{K}^{+}$secretion in human distal colon driven by prostaglandin $\mathrm{E}_{2} . \operatorname{Am~} \mathcal{f}$

78 Berschneider HM, Powell DW. Fibroblasts modulate intestinal secretory responses to inflammatory mediators. F Clin Invest 1992;89:484-9.

79 Compeau C, Rotstein O, Tohda H, et al. Endotoxin stimulated alveolar macrophages impair lung epithelial $\mathrm{Na}^{+}$transport by an L-arg dependent mechanism. Am F Physiol 1994;266:C1330-41.

80 Ciacci C, Mahida Y, Dignass A, et al. Functional interleukin-2 receptors on intestinal epithelial cells. F Clin Invest 1993;92:527-32.

81 Madsen KL, Tavernini MM, Mosmann TR, et al. Interleukin 10 modulates ion transport in rat small intestine. Gastroenterology 1996;111:936-44.

82 Shapiro M, Matthews J, Hecht G, et al. Stabilization of F-actin prevent cAMP-elicited $\mathrm{Cl}^{-}$secretion in T84 cells. F Clin Invest 1991;87:1903-9.

83 Matthews JB, Awtrey CS, Madara JL. Microfilament dependent activation of $\mathrm{Na}^{+} / \mathrm{K}^{+} / 2 \mathrm{Cl}^{-}$co-transport by cAMP in intestinal epithelial monolayers. $\mathcal{F}$ Clin Invest 1992;90:1608-13.

84 Opleta-Madsen K, Hardin J, Gall DG. Epidermal growth factor upregulates intestinal electrolyte and nutrient transport. Am f Physiol 1991;260:G80714

85 Uribe JM, Gelbmann CM, Traynor-Kaplan AE, et al. Epidermal growth factor inhibits $\mathrm{Ca}^{2+}$ dependent $\mathrm{Cl}^{-}$transport in T84 human colonic epithelial cells. Am f Physiol 1996;271:C914-22.

86 Uribe JM, Keely SJ, Traynor-Kaplan AE, et al. Phosphatitidyl-inositol 3-kinase mediates the inhibitory effect of epidermal growth factor on
calcium-dependent chloride secretion. F Biol Chem 1996;271:26588-95.

87 Borok Z, Hami A, Danto S, et al. Effects of EGF on alveolar epithelial junctional permeability and active sodium transport. Am F Physiol 1996;270. L559-65.

88 Hecht G, Pestic L, Nikcevic G, et al. Expression of the catalytic domain of myosin light chain kinase increases paracellular permeability. Am F Physiol 1996;271:C1678-84.

89 Shanahan F. Designer drugs for inflammatory bowel diseases. Gastroenterology 1997;112:2153-8.

90 Neurath MF, Pettersson S, Meyer zum Buschenfelde KHM, et al. Local administration of antisense phosphorothioate oligonucleotides to the p65 subunit of NF- $\mathrm{kB}$ abrogates established experimental colitis in mice. Nat Med 1996;2:998-1004.

91 Keates S, Hitti YS, Upton M, et al. Helicobacter pylori infection activates NF-кB in gastric epithelial cells. Gastroenterology 1997;113:1099-109.

92 Jobin C, Haskill S, Mayer L, et al. Evidence for altered regulation of I $\mathrm{B}$ degradation in human colonic epithelial cells. F Immunol 1997;158:226-34.

93 Ihle JN. STATs: signal transducers and activators of transcription. Cell 1996;84:331-4.

94 Reinecker H, MacDermott RP, Mirau S, et al. Intestinal epithelial cells both express and respond to interleukin 15. Gastroenterology 1996;111:1706-13.

95 Warhurst AC, Hopkins SJ, Warhurst G. Intereferon $\gamma$ induces differential upregulation of $\alpha$ and $\beta$ chemokine secretion in colonic epithelial cell lines. Gut 1998;42:208-213.

96 Grimm MC, Elsbury SKO, Pavli P, et al. Interleukin 8: cells of origin in inflammatory bowel disease. Gut 1996;38:90-8.

97 Kuhn R, Lohler J, Rennick D, et al. Interleukin-10 deficient mice develop chronic enterocolitis. Cell 1993;75:263-74.

98 Sadlack B, Merz H, Schorle H, et al. Ulcerative colitis-like disease in mice with a disrupted interleukin-2 gene. Cell 1993;75:253-61. 
99 Sartor RB. The role of enteric microflora in the pathogenesis of intestinal inflammation and arthritis. Aliment Pharmacol Ther 1997;11(suppl inflammation

100 Sears C, Kaper J. Enteric bacterial toxins: mechanisms of action and linkage to intestinal secretion. Microbiol Rev 1996;60:167-215.

101 Yamada T, Sartor RB, Marshall S, et al. Mucosal injury and inflammation in a model of chronic granulomatous colitis in rats. Gastroenterology 1993; 104:759-71

102 Rook GAW, Stanford JL. Give us this day our daily germs. Immunol Today 1998;19:113-16.

103 Strober W, Kelsall B. To be responsive or not to be responsive, that is the mucosal question. Gastroenterology 1998;114:214-17.

104 Eldridge JH, Staas JK, Chen D, et al. New advances in vaccine delivery systems. Semin Hematol 1993;30:16-25.

105 Powell MF. Drug delivery issues in vaccine development. Pharmacol Res 1996;13:1777-85.

106 Trinchieri G. Interleukin 12: a cytokine produced by antigen-presenting cells with immunoregulatory functions in the generation of T-helper cells cells with immunoregulatory functions in the generation of
type 1 and cytotoxic lymphocytes. Blood 1994;84:4006-27.

107 Marinaro M, Boyaka PN, Finkelman FD, et al. Oral but not parenteral interleukin (IL)-12 redirects T helper 2 (Th2)-type responses to an oral vaccine without altering mucosal IgA responses. f Exp Med 1997;185:415-27.
108 Monteleone G, Biancone L, Marasco R, et al. Interleukin 12 is expressed and actively released by Crohn's disease intestinal lamina propria mononuclear cells. Gastroenterology 1997;112:1169-78.

109 Duchmann R, Kaiser I, Hermann E, et al. Tolerance exists towards resident intestinal flora but is broken in inflammatory bowel disease (IBD). Clin Exp Immunol 1995;102:448-55.

110 Bramson JL, Graham FL, Gauldie J. The use of adenoviral vectors for gene therapy and gene transfer in vivo. Curr Opin Biotech 1995;6:590-5.

111 Jobin C, Panja A, Hellerbrand C, et al. Inhibition of proinflammatory molecule production by adenovirus mediated expression of a nuclear factor $\mathrm{\kappa B}$ super-repressor in human intestinal epithelial cells. F Immunol 1998;160: super-repre

112 Hyde SC, Gill DR, Higgins G, et al. Correction of the ion transport defect in cystic fibrosis transgenic mice by gene therapy. Nature 1993;362: 250-4.

113 Brown GR, Thiele DL, Silva M, et al. Adenoviral vectors given intravenously to immunocompromised mice yield stable transduction of the colonic epithelium. Gastroenterology 1997;112:1586-94.

114 Croyle MA, Walter E, Janich S, et al. Role of integrin expression in adenovirus-mediated gene delivery to the intestinal epithelium. Hum Gene Ther 1998;9:561-73. 